\title{
CONHECIMENTO HISTÓRICO DO HISTORIADOR E OUTROS CONHECIMENTOS HISTÓRICOS
}

\author{
Bruno Flávio Lontra Fagundes 1
}

\begin{abstract}
Resumo
O presente artigo trata dos conhecimentos históricos não-profissionais socialmente disseminados que concorrem com o conhecimento histórico do historiador profissional. A premissa de que se parte é reconhecer a legitimidade destes outros conhecimentos, abordando-os por meio de autores diversos, sem deixar de lado aqueles que falam numa perspectiva inglesa e americana, esta, em especial, com alguns aspectos com que boa parte da historiografia da história pública brasileira pouco dialoga - como o aspecto da empregabilidade (pensando, talvez, que tudo que se faz nos Estados Unidos seja com fins mercantis, exclusivamente) e a convivência profícua entre cursos de formação em história acadêmica com outros de formação em história pública. Objetivo, aqui, sopesar o conhecimento treinado num curso que cria o historiador profissional no Brasil segundo uma pretensão de fazer conhecimento para o público, ponderando se esta perspectiva não retém um componente que contém uma premissa da superioridade da história metodológica e cientificamente orientada ante a história não-profissional do conhecimento comum. Minha indagação aqui é se, em alguma medida, as premissas de parte da História Pública discutida e praticada no país não são informadas por um postulado cujo objetivo é o de levar o conhecimento sábio profissional a públicos insipientes, postulado a meu ver perigoso, porque hierarquizante, em que o conhecimento do historiador ainda é visto como superior a outros demais conhecimentos não produzidos na academia - mesmo em se levando em conta as múltiplas definições e objetos de análise da História Pública brasileira que a tornam tão diversificada e rica.
\end{abstract}

Palavras-chave: Ciência do historiador; Insciência histórica comum; Hierarquia de saberes.

\begin{abstract}
This article deals with the socially scattered historical knowledge that adresses the competitor's issue with the professional's historical knowledges. The starting premise is to recognize the legimacy of this other knowledge, approaching it through different authors, without leiving aside those who speak in an English and American perspective, this, in particular, with some aspects with which much of the historiography of Brazilian public history has little dialogue - as the aspect of employability (thinking, perhaps, that everything that is done in the United States is for commercial purpose, exclusively) and the fruitful coexistence between training courses in academic history with other training courses in public history. The objective here is to weigh the knowledge trained in a course that creates the professional historian in Brazil according to a claim to make knowledge for the public, pondering whether this perspective does not retain a component that contains a premise of the superiority of methodological and scientifically oriented history over the non-professional history of common knowledge. My question here is whether, to some extent, the premises of part of public history discussed and practiced in the country are not informed by a postulate whose objective is to take wise professional knowledge to incipient audiences, postulate dangerous, in my view, because hierarchical in which the historians knowledge is still seen as superior to other knowledge not produced in academia - even so, taking into account the multiple definitions and object of analysis of Brazilian Public History that become so diverse and rich.
\end{abstract}

Keywords: Historian science; Common historical awareness; Knowledge hierarchy.

\footnotetext{
1 Professor efetivo da Universidade Estadual do Paraná (UNESPAR), campus de Campo Mourão. Professor vinculado ao PPG em História Pública e ao Mestrado Profissional em Ensino de História (PROFHISTORIA), ambos da UNESPAR. E-mail: parabrunos@gmail.com
} 


\section{Considerações iniciais}

Em entrevista concedida a Francesco Maiello, em 1982, intitulada “A história, o historiador e os Mass Media" (grifo do autor), Jacques Le Goff responde à pergunta sobre "o lugar dos historiadores nas sociedades ocidentais". Inserindo em seu raciocínio, como não poderia deixar de ser, as mutações promovidas pelas mídias no fazer historiador e mesmo no estatuto de autoridade do historiador, mesclado a comparações entre a Nova História e o Positivismo, Le Goff corrige seu entrevistador. Este indagava se o desprestígio naquele momento do historiador "aos olhos de quem governa", só lhe deixava o grande público, situação considerada "desesperante". Le Goff imediatamente conserta o que pode ter sido entendido das suas considerações: “(...) quando falei de êxito e de triunfo [da história junto ao grande público], falei da história e não do historiador"”2. História e não historiador, eis aí distinção fundamental.

As discussões travadas no universo historiográfico francês nos anos 1970 e início dos anos 1980 parecem-me bastante sugestivas para se pensar a questão das mutações do papel do historiador, sua função social, relativamente a um contexto onde o grande público se interessa por e consome história.

Por ocasião de uma mesa-redonda promovida pela revista Magazine Littéraire na segunda metade dos anos 1970 - cujos debates foram publicados pelo mesmo periódico em abril de 1977 - Jacques Le Goff, Emmanuel Le Roy Ladurie, Georges Duby, Paul Veyne, Michel de Certeau, Philippe Ariés, Pierre Nora e outros [sic] foram discutidos vários temas, entre eles, que mais nos interessa aqui, a explosão midiática da história - da qual alguns destes historiadores assumiam participar - , e as mutações da história provocadas pela Nova História, mas, e acima de tudo, os desdobramentos sobre o papel e o lugar social do historiador, tendo que "justificar a necessidade e a urgência de seu trabalho" ${ }^{3}$. Sem entrar no mérito de que a discussão em curso - na realidade, as discussões em curso na historiografia mundial sobre o problema da função social da História - já contivessem um princípio da discussão sobre a História Pública - na realidade sobre o que importava, e como, a história a outros públicos - sem entrar neste mérito, então, em meio àquela discussão a qual mencionava a força da história produzida pelas mídias por não-profissionais de História (embora alguns assumissem que participavam daquelas mídias!), em meio à discussão o entrevistador

\footnotetext{
${ }^{2}$ LE GOFF, Jacques. Reflexões sobre a História. Lisboa, PO: Edições 70, 2009

${ }^{3}$ ARIÉS, Philippe et al. A história - uma paixão nova. In: LE GOFF; LADURIE; DUBY.et al. A Nova História. Lisboa, PO: Edições 70, 2009
} 
indaga sobre como ficavam eles, historiadores, com o "fato de serdes apanhados por este fenômeno de expansão" [da história nas mídias] $]^{4}$. Michel de Certeau, que participava da entrevista, ${ }^{5}$ alega que o fenômeno deveria ser pensado na perspectiva de a autoridade histórica se tornar uma "vedete", embora seu principal argumento fosse “deter-me num problema que o êxito da História nos mass-media introduz na profissão"6.

\begin{abstract}
(...) A reflexão sobre a produção, quer dizer, a metodologia, insistiu sempre mais no inventário, na classificação, e no tratamento das fontes do que na construção do discurso. Ora, a passagem do livro especializado ao filme e à emissão televisionada exige que se repense a relação existente entre o trabalho profissional da investigação (também ele modificado) e a representação historiográfica. Há que se indagar também a respeito da "encenação" da História, no momento em que se multiplicam as suas possibilidades e em que ela se inscreve mais manifestamente como uma variante dentro do campo mais vasto do espetáculo. Em que medida é histórica uma representação literária ou filmada? Como é o discurso histórico, é um espetáculo específico? ${ }^{7}$
\end{abstract}

Considerando a escrita como manifestação apropriada pela qual se divulga o trabalho da pesquisa histórica internamente aos membros da disciplina - "Os seus efeitos de sedução ou de autoridade não são, aliás, estranhos ao próprio papel da história, ontem e hoje, no grande público" - Michel de Certeau abre a perspectiva sobre o trabalho da divulgação e da apresentação do conhecimento histórico especialista.

\begin{abstract}
A metodologia atua como se tudo se passasse nos arquivos, grutas onde nasceriam os historiadores, e como se a própria produção fosse "literatura" pertencente à genialidade individual dos heróis saídos dessas cavernas. De fato, a História, arte de tratar os restos, é também uma arte da encenação, e as duas estão estreitamente ligadas ${ }^{8}$.
\end{abstract}

Jacques Le Goff discorre, ainda, na mesma entrevista "A história, o historiador e os Mass Media" dada a Francesco Maiello, de 1982, sobre os "muitos problemas novos" postos aos historiadores pelo fato destes terem descoberto para falar ao "grande público", novos "meios particularmente sedutores: rádio, televisão, publicações de

\footnotetext{
${ }^{4}$ ARIÉS, Philippe et al. A história - uma paixão nova. In: LE GOFF; LADURIE; DUBY.et al.A Nova História. Lisboa, PO: Edições 70, 2009

${ }^{5}$ Participavam da entrevista Michel de Certeau, Philippe Ariés, Jacques Le Goff, Emmanuel Le Roy Ladurie e Paul Veyne.

${ }^{6}$ ARIÉS, Philippe et al. A história - uma paixão nova. In: LE GOFF; LADURIE; DUBY.et al.A Nova História. Lisboa, PO: Edições 70, 2009

${ }^{7}$ ARIÉS, Philippe et al. A história - uma paixão nova. In: LE GOFF; LADURIE; DUBY.et al.A Nova História. Lisboa, PO: Edições 70, 2009

${ }^{8}$ ARIÉS, Philippe et al. A história - uma paixão nova. In: LE GOFF; LADURIE; DUBY.et al.A Nova
}

História. Lisboa, PO: Edições 70, 2009 
vastíssima tiragem”. Discutindo a perda de prestígio de historiadores junto ao poder, compensado pela projeção sobre o grande público, Le Goff destaca "uma coisa de importância capital": "De fato, estou cada vez mais convencido de que a história não poderá manter uma qualquer função no âmbito da ciência e da sociedade se os historiadores não souberem por-se em dia no que se refere aos novos meios de comunicação de massa"9.

A discussão posta acima neste artigo refere-se aos claros problemas a historiadores de corte profissional e de formação tradicional mais erudita - como a dos historiadores oitocentistas, para quem sua autoridade derivava de a "história não estar ainda separada da literatura e de o historiador ser alguém que tem também a preocupação estética de escrever bem"10.

Pari passu aos efeitos aqui mencionados para a disciplina histórica da "intromissão" dos mass media no artesanato do historiador - inclusive a natureza de sua investigação em vista de como apresentará os resultados de seu trabalho - tenho em mente avaliar as mutações que forçam os profissionais da história a adequarem-se a procedimentos de difusão novos e que expandem o campo, ao mesmo tempo que ponderar se este processo é acompanhado de uma mudança da percepção de si mesmos.

Em outras palavras: se os procedimentos de difusão do conhecimento histórico acadêmico vêm acompanhado não só das mudanças técnicas ligadas àquela difusão, mas se também vêm acompanhadas de alguma auto-percepção alterada de seu papel social e da autoridade que um dia teve manifestada em algum prestígio social. Porque, perguntome, se adiantará muito que as mudanças técnicas não venham acompanhadas de uma mudança de mentalidade dos historiadores sobre seu papel social e sobre si mesmos. A História Pública, a meu ver, coloca esta questão de maneira contundente: não só o historiador sabe história, o historiador precisa saber ouvir os públicos com o reconhecimento da autoridade dos que vivem história, e que, bem ou mal, acreditam sabê-la. São "autoridades compartilhadas"11. Uma e outra coisas precisarão andar juntas, a meu ver, uma vez que tratar-se o historiador a si mesmo como alguém com um conhecimento melhor do que o de outros públicos será desprezar um dos princípios

\footnotetext{
${ }^{9}$ LE GOFF, Jacques. Reflexões sobre a História. Lisboa, PO: Edições 70, 2009.

${ }^{10}$ LE GOFF, Jacques. Reflexões sobre a História. Lisboa, PO: Edições 70, 2009.

${ }^{11}$ FRISCH, Michael. A história pública não é uma via de mão única o de a Shared Authority à cozinha digital, e vice-versa. In: MAUAD, Ana M; ALMEIDA, Juniele R de.; SANTHIAGO, Ricardo. (Orgs.)

História Pública no Brasil. Sentidos e Itinerários. São Paulo, SP: Letra e Voz, 2016.
} 
básicos sobre o qual assenta-se a História Pública em seu processo de valorizar outros públicos e de lhes conferir uma necessária autoridade.

\section{Algumas palavras sobre história, mas também comunicação, envolvidas na divulgação}

O historiador Thomas Cauvin refaz o movimento da História Pública em dois grandes momentos. O dos anos 1970 - quando imperou uma História Pública a maneira americana, focada na procura de empregos e numa quase obsessão com o que identificava o isolamento do historiador na "torre de marfim", ${ }^{12}$ e um segundo momento em que "as definições de história pública se transformaram com o tempo". E este processo de transformação pode ter sua virada datada dos anos 1990: "na década de 90, as perspectivas de todos aqueles historiadores europeus e estadunidenses seriam fusionadas e a História Pública estadunidense seria redefinida como 'história para o público, sobre o público e feita pelo público"”. Segundo Cauvin, "tal movimento foi parte de uma abordagem por parte das instituições culturais sobre o público e as audiências, do que redundou a realidade de que "comunicar a história a audiências nãoacadêmicas se tornou ainda mais importante (...)"13.

Boa parte das discussões sobre História Pública contém uma proposição a meu ver adequada, que valoriza o conhecimento acadêmico de história como indispensável. "Não se trata de (...) abrir mão de princípios teóricos, metodológicos e éticos na produção do conhecimento histórico, aceitando que história é só versão""14. A mesma discussão traz outra proposição em cujo bojo, pode estar, implícita, a ideia de que o conhecimento do historiador acadêmico deve procurar se adaptar ao conhecimento daqueles que são não-treinados em História - e uma hipótese aqui é avaliar se o conhecimento acadêmico ainda se acha superior a ponto de acreditar que é questão de mera adaptação para que o outro apenas entenda o conhecimento já formulado na academia, já que, sem interação, adaptar não é reelaborar. "O que me preocupa na

\footnotetext{
$12 \mathrm{O}$ historiador americano Theodore Hamerow associa o isolamento dos historiadores na "torre de marfim" ao processo de profissionalização e de "burocratização" da história, refazendo a trajetória deste isolamento desde o século XIX que cientificizou a história, trajetória agudizada após a Segunda Grande Guerra. "Estas são as preocupações de uma disciplina que retirou-se dos perigos da literatura e profetiza para tornar-se parte do currículo de faculdade". [Such are the concerns of a discipline thas has withdrawn from the hazards of literature and prophesy to become part of the college curriculum] (HAMEROW, 1989, p.659). Todas as traduções dos trechos em inglês foram feitas por mim.

13 CAUVIN, Thomas. Uma ascensão da história pública: uma perspectiva internacional. Revista NUPEM, v.11, n.23, p. 8-28, 2019.

${ }^{14}$ HERMETO, Miriam \& FERREIRA, Rodrigo de A. Apresentação de dossiê. Revista História Hoje, v.8, n.15, p.5-16, 2019.
} 
História Pública é essa ideia de que todo mundo pode fazer história (...) Acho que tem uma dose de risco quando você acha que qualquer pessoa, qualquer cidadão está habilitado e legitimado para escrever um trabalho, digamos, científico sobre história"15. A afirmação de Ferreira indica a adesão a uma realidade capciosa do processo de comunicar história a audiências de não-pares, assim como uma defesa de área acadêmica.

Já Marta Rovai alerta para os perigos de uma história sem o crivo da área: "é preciso considerar que sem o conhecimento histórico, acumulado e sistematizado sobre os processos humanos, corre-se o risco de simplificações históricas, preconceitos e indiferenças" $"$.

Estas afirmações, adequadas e cuidadosas, de Rovai e Ferreira precisam ser nuançadas por colocações que admitam certa forma de as próprias audiências produzirem suas histórias - sem precisar esperá-las pela divulgação -, mesmo sem a benção dos profissionais acadêmicos, como Stephen Bann já desenvolveu sobre os inícios da história disciplinarizada inglesa. Carlyle e Macaulay (...) "talvez as mais duas célebres figuras da historiografia britânica do século XIX (...) mantiveram a distância da cada vez maior comunidade de historiadores profissionais e deliberadamente abstiveram-se de aderir às instituições [universitárias] recém-fundadas"17. Ao trabalharem com memes como forma de difusão de história "para um público amplo" como práticas de Ensino, Costa \& Mendes apontam para o "aspecto mítico" das formulações sobre história. "O que se propõe aqui é que o educador deve levar em consideração o aspecto mítico, presente no imaginário do aluno sobre um personagem histórico" ou - em outras palavras - levar em conta formulações sobre história que o horizonte de expectativa de análise de historiadores disciplinarizados normalmente não visam, uma vez que não só leem história segundo critérios de um conhecimento especializado, como nem sempre consideram fatores de um outro tipo de escrita histórica das audiências, que a fazem segundo a projeção de mitos sobre a relação passado e presente.

\footnotetext{
${ }^{15}$ FERREIRA, Marieta de Moraes. Uma trajetória em (o que chamamos hoje) História Pública. Revista História Hoje, v.8, n.15, p.223-238, 2019. Entrevista concedida a Miriam Hermeto e Rodrigo de Almeida Ferreira.

${ }^{16}$ ROVAI, Marta G. de O. Publicizar sem simplificar: o historiador como mediador ético. In: ALMEIDA, Juniele R de; MENESES, Sônia (Orgs.). História Pública em debate: patrimônio, educação e mediações do passado. São Paulo, SP; Editora Letra e Voz, 2018.

${ }^{17}$ BANN, Stephen. As invenções da história: ensaios sobre a representação do passado. Ed. UNESP, 1994.
} 
Autores como Ludmila Jordanova referem-se às dificuldades de "engajar o público maior no debate histórico, especialmente quando eles mesmos têm pouca conexão com os debates em questão". Além do que públicos preferem tipos de história que estão, aparentemente, em desacordo total com os procedimentos dos historiadores profissionais: "Por que muitas pessoas preferem narrativas sobre o passado que sejam, de um ponto de vista de historiadores, demonstradamente falsas, inexatas?". ${ }^{18}$

Em algumas ocasiões, Ricardo Santhiago expressou seu entendimento do que seriam as dimensões com que a história pública opera. Seguindo o autor, como tipos de História Pública, os "quatro engajamentos fundamentais, passíveis de entrecruzamento (...)” [da história pública $]^{19}$ são a história para públicos, com públicos, pelos públicos e $e$ públicos. Para fins deste texto, trabalho com a dimensão da história para o público, e ao analisar o website inglês Doing Public History (Fazendo História Pública), Hilda Kean escolhe avaliar, dentre as "várias definições de história pública", aquela que "se baseia na forma e natureza de transmissão do conhecimento histórico a audiências ampliadas", ocasião em que a história é "tomada como dada".

(...) Tais definições implicam que o historiador, usualmente visto como um profissional treinado, está executando um papel ativo e o "público" um papel passivo. O ônus está sobre o historiador para garantir que o corpo do conhecimento transmitido esteja acessível. Isto tem o efeito dual de engajar "o público", mas também de reforçar o status separado do historiador como o disseminador que processa não apenas conhecimento, mas a habilidade de transmissão. 20

Na modalidade de História Pública como história para o público, autores desejam que a história acadêmica abandone a famigerada "torre de marfim", e se aproxime mais de públicos que recebem o passado de diversos modos. "Amplia-se na academia o debate em torno da necessidade urgente de organização, mediação e

\footnotetext{
${ }^{18}$ how to engage the wider public in historical debate, especially when they themselves have little connection to the debates in question .... [e] .... Why do so many people prefer accounts of the past that are, from a historian's point of view, demonstrably untrue? Este texto foi originalmente publicado no site History \& Policy, uma rede social que envolve mais de 500 historiadores, iniciativa do Kings College, em Londres, e da Universidade de Cambridge. O texto foi publicado em novembro de 27 de novembro de 2008 e não têm numeração de páginas. Ver: JORDANOVA, Ludmila. Como a história importa hoje? Disponível em: http://www.historyandpolicy.org/policy-papers/papers/how-historymatters-now. Publicado em novembro de 2008. Acesso em janeiro 2019.

${ }^{19}$ SANTHIAGO, Ricardo. (Orgs.) História Pública no Brasil. Sentidos e Itinerários. São Paulo, SP: Letra e Voz, 2016.

${ }^{20}$ Such definitions imply that the historian, usually seen as professionally trained, is performing an active role and the "public" a passive one. The onus therefore is upon the historian to ensure that the body of knowledge transmitted is accessible. This has the dual effect of engaging "the public" but also of enhancing the separate status of the historian as the disseminator who possesses not only knowledge but the skill of transmission. Ver: KEAN, Hilda. Pessoas, historiadores e História Pública. The Public Historian, v.32, n.3, 2010.
} 
divulgação dos mais diferentes saberes, de forma que possa abranger e contar com a participação e o diálogo com comunidades diversas, para além das universidades e das escolas" ${ }^{21}$ sob a alegação de que a "academia tem sido omissa em considerar seriamente este tipo de historiografia produzida para o público, à margem do que se faz stricto sensu nas escolas de formação superior (...)"22.

A boa história divulgada que visasse a públicos não aconteceria, também, por questão de linguagem difícil dos historiadores. Embora não possa ser confundida com reducionismos ou saber banal, o "uso de uma linguagem mais acessível"23é um objetivo a ser alcançado. Ouve-se muito da parte de públicos interessados, mas não formados que "o historiador precisa aprender a escrever mais fácil, numa linguagem mais acessível", que os historiadores são herméticos, escrevem difícil. Se entendida como divulgação, a História Pública para o público teria aí um empecilho, mesmo que a História Pública reconheça que "nós, historiadores, não somos os únicos capazes de produzir um conhecimento histórico legítimo" 24.

Como se, um, a história pública se reduzisse a isso - o que não é irrazoável, uma vez que nem os historiadores sabem exatamente o que seja História Pública; e, dois, como se a recepção de textos fosse motivada apenas por um processo comunicacional, em que o outro recebesse de um aquilo que quer escutar, ler ou ouvir, mas que aquele que comunica não conseguisse fazer bem, por causa de sua linguagem hermética, pouco adequada e desagradável, quando não inatingível. Não é inquestionável que o processo de produção de conhecimento histórico orientado, científica e academicamente, exija algum fechamento e hermetismo, mas perguntas e abordagens feitas ao passado por grupos de especialistas sobre certos passados de interesse mais geral não são as mesmas perguntas e abordagens que o público em geral faz aos mesmos passados.

Tratado muitas vezes como textos publicados em veículos e meios de massa de grande circulação, o que faltaria à divulgação é o bom redator, como o jornalista, que

\footnotetext{
${ }^{21}$ ROVAI, Marta G. de O. Publicizar sem simplificar: o historiador como mediador ético. In: ALMEIDA, Juniele R de; MENESES, Sônia (Orgs.). História Pública em debate: patrimônio, educação e mediações do passado. São Paulo, SP; Editora Letra e Voz, 2018.

22 ALBIERI, Sara. História pública e consciência histórica. ALMEIDA, Juniele Rabêlo de \& ROVAI, Marta Gouveia de Oliveira. Introdução à História Pública. São Paulo: Letra e Voz, 2011.

${ }^{23}$ PENNA, Fernando de Araujo \& FERREIRA, Rodrigo de Almeida. O trabalho intelectual do professor de História e a construção da educação democrática. Prática de História Pública frente à Base Nacional Comum Curricular e ao Escola Sem Partido. In: História Pública em debate: patrimônio, educação e mediações do passado. São Paulo, SP; Editora Letra e Voz, 2018.

${ }^{24}$ MAUAD, Ana M; ALMEIDA, Juniele R de.; SANTHIAGO, Ricardo. (Orgs.) História Pública no Brasil. Sentidos e Itinerários. São Paulo, SP: Letra e Voz, 2016. Resenha de: CORRÊA, Luiz Otávio. Os vários significados da História Pública. Revista Transversos, Rio de Janeiro, v.7, n.7, set.2016.
} 
tem uma prosa acessível e agradável. Ao profissionalizar-se, o historiador teria perdido um de seus elos mais fortes, o elo com a literatura - "alguém que tem também a preocupação estética de escrever bem", como diz Le Goff ${ }^{25}$. Mas a História Pública tem variado suas linguagens/narrativas de divulgação - literárias, fílmicas, linguagens virtuais, expográficas, radiofônicas - realidade sempre repisada.

Eu acho que a tarefa da História Pública é compreender e expandir a audiência para o conteúdo histórico e isso pode ser feito, mais uma vez, pela radioteledifusão, pela apresentação popular dos materiais, o que pode ser pela hipermídia, em um jogo, em um documentário radiofônico, ou uma exposição estilosa ${ }^{26}$.

Ao mesmo tempo, públicos não se perguntam se a prosa agradável é história boa, se a complexidade eventual dos objetos de que se trata foi mantida, não se pergunta se houve "simplificação de padrões de divulgação"27: "não é fácil dizer de modo simples o essencial ${ }^{28}$.Assim como públicos não são fixados em checar se há atenção mínima a padrões do conhecimento histórico científica e academicamente validados. Afinal, para Jurandir Malerba, há bons historiadores e historiadores ruins dentro e fora da academia, mas:
aqui dentro [da academia], faz parte do ofício o processo permanente da metodização racional dos procedimentos e exposição dos argumentos e a crítica (das fontes, dos procedimentos de coleta e sistematização dessas fontes, de problematização temática e perspectivação teórica, de produção textual). Esses mesmos protocolos, esse mesmo padrão de exigência deve ser aplicado a toda historiografia, acadêmica ou não (MALERBA 2 2014, p.44).

Ao tratar das possíveis definições de História Pública e da divulgação do conhecimento para o público, Santhiago também previne de alguns cuidados necessários. Para o autor, provavelmente a divulgação de história requereria uma mudança na forma da pesquisa histórica, o que qualifica de "história predisposta à divulgação". Assim: "A história pública engloba um conjunto de qualificativos que,

\footnotetext{
${ }^{25}$ LE GOFF, Jacques. Reflexões sobre a História. Lisboa, PO: Edições 70, 2009.

26 SANTHIAGO, Ricardo. "A História Pública é a institucionalização de um espírito que muitos historiadores têm tido, por milhares de anos": Uma entrevista com David King Dunaway sobre História Oral, História Pública e o passado nas mídias. Revista Transversos. "Dossiê: História Pública: Escritas Contemporâneas de História". Rio de Janeiro, Vol. 07, nº 07, pp. 203-222, Ano 03. set. 2016. Disponível em: <http://www.e-publicacoes.uerj.br/index.php/transversos>. ISSN 2179-7528. DOI: 10.12957/transversos.2016.25607.

${ }^{27}$ ROVAI, Marta G. de O. Publicizar sem simplificar: o historiador como mediador ético. In: ALMEIDA, Juniele R de; MENESES, Sônia (Orgs.). História Pública em debate: patrimônio, educação e mediações do passado. São Paulo, SP; Editora Letra e Voz, 2018. p.185-196.

28 ALBIERI, Sara. História pública e consciência histórica. ALMEIDA, Juniele Rabêlo de \& ROVAI, Marta Gouveia de Oliveira. Introdução à História Pública. São Paulo: Letra e Voz, 2011
} 
salvo engano, requer modificações durante todo o processo de pesquisa e não apenas no momento de seu escoamento". Suplementando sua reflexão que recusa as opiniões favoráveis a que uma "boa história" a ser divulgada é simples questão de linguagem acessível, palatável, ou coisas assim, ele reafirma:

\begin{abstract}
Mais uma vez, me parece que este campo, entendido como um lugar de debate, é o que tem permitido superar a visão da história pública como "questão de linguagem", embora ela continue à espreita - e deva ser vista com muita prudência, porque pode ser facilmente empregada para a deslegitimação desse lugar ${ }^{29}$.
\end{abstract}

É importante ter em mente aspectos que provêm dos "cacoetes acadêmicos", mas também do que seria uma adesão dos públicos a histórias sem o devido balizamento acadêmico. O conhecimento histórico divulgado para o público não é mera questão de linguagem fácil e acessível pouco executada por especialistas e/ou materiais ilustrados, ao mesmo tempo em que os historiadores devem admitir que “existe uma produção de bom nível, legível e acessível para um público não especializado, perfeitamente adequada ao território intermediário entre a cultura comum e aquela especializada, produzida na Academia"30. A academia não deve dar a entender que:

\begin{abstract}
antes de tornar-se público, o conhecimento histórico se acumula ocultamente, assumindo uma forma precisa. Trata-se de uma concepção do conhecimento histórico como algo objetivo, cumulativo, que possa ser controlado e possuído por alguém. Nesta concepção está embutida a crença de aquilo que está guardado contém algum tipo de verdade objetiva e inequívoca. É como se o acesso a certos documentos fosse tudo o que falta para que a revelação iluminadora da verdade histórica finalmente ocorra ${ }^{31}$.
\end{abstract}

Algo da natureza do passado e das abordagens e perguntas feitas a ele não interessaria ao público em geral, mas a historiadores em especial, internamente a seu ofício, e uma divulgação não deve ser medida por uma régua comunicacional linguística: palavras mais coloquiais, linguagens mais comuns, vocabulário de todos pelo menos de muitos textos conceituados, que fariam do passado algo mais acessível independente de sua abordagem. Não!

\footnotetext{
${ }^{29}$ SANTHIAGO, Ricardo. Duas palavras, muitos significados: alguns comentários sobre a história pública no Brasil. In: MAUAD, ALMEIDA, Juniele Rabelo de; SANTHIAGO, Ricardo (Orgs.). História Pública no Brasil: Sentidos e Itinerários. SP: Editora Letra e Voz, 2016. p.23-36.

${ }^{30}$ ALBIERI, Sara. História pública e consciência histórica. ALMEIDA, Juniele Rabêlo de \& ROVAI, Marta Gouveia de Oliveira. Introdução à História Pública. São Paulo: Letra e Voz, 2011.

${ }^{31}$ ALBIERI, Sara. História pública e consciência histórica. ALMEIDA, Juniele Rabêlo de \& ROVAI, Marta Gouveia de Oliveira. Introdução à História Pública. São Paulo: Letra e Voz, 2011.
} 
Analisado de um ponto de vista estritamente linguístico, texto bem escrito - o que quer que isto signifique - não é o suficiente. Até porque muitas vezes o leitor, só de saber que é História, Sociologia, Filosofia, nem se dispõe a ver, a ler. Afinal, o que é um texto bem escrito? Ele é agradável porque adorna e ornamenta, para dizer com Homero, ou ele é um “ensinamento para sempre”, para dizer com Tucídides?

Entre emissor de mensagens e seus receptores deve haver uma identidade de propósitos e valores quando são analisados os passados que são pesquisados e divulgados. Por que muitos passados divulgados não são aceitos, sem linguagem agradável? Só porque não há linguagem acessível? Beatriz Sarlo acredita que haja uma situação de memórias confortáveis e aprazíveis quando estão em jogo significados comunicados do passado: muitos passados não agradam porque eles dizem memórias que não consolam, e os sujeitos procurariam no passado exatamente conforto. "As visões do passado embutidas em modalidades não-acadêmicas de texto", quando comparadas a textos acadêmicos, garantem sentido e "consolo" uma vez que se "duplicam modos de percepção social que não apresentam contradições com o senso comum de seus leitores, mas o sustentam e se sustentam nele" ${ }^{\text {"2 }}$. Os receptores não aceitariam a história que não fosse memória se não identificassem nela algo de si mesmos, sem contradições, desconfortos e impessoalidades.

\section{A história afetivamente envolvente, passados que sensibilizam públicos e possíveis} hierarquias

É por essas e outras que para a história pública para o público não basta apenas uma história que tenha passado pelo crivo da academia transmitida de modo agradável.

Numa formulação a fim de sugerir o que não deveria faltar a uma definição de história pública, a historiadora Ludmila Jordanova ressalta que os vínculos os quais sujeitos estabelecem com o passado são sempre pessoais, mediados por suas emoções e sentimentos, por meio dos quais o passado vem a cada um de nós, e que só poderiam ser contados, e aceitos, se garantissem aos sujeitos a história como parte de suas histórias de vida pessoal, narrativas que pudessem ser ditas por meio de histórias que viveram e que, de algum modo, os enlaçaram e/ou lhes tocaram. Não existiria história que não fosse vivida nesta perspectiva, digamos, personalista.

\footnotetext{
${ }^{32}$ SARLO, Beatriz. Tempo Passado. Cultura da Memória e Guinada Subjetiva. São Paulo (SP): Cia das Letras; Belo Horizonte (MG): Editora UFMG, 2007.
} 
Por que pessoas sem motivação direta profissional, poriam atenção particular às complexidades da história? Aqui eu entendo história num sentido forte uma disciplina formal que demanda habilidades especializadas, expertise e conhecimento, incluindo um entendimento crítico de fontes materiais e uma familiaridade com uma variedade ampla de maneiras com as quais evidências podem ser interpretadas. ${ }^{33}$

A acepção da História Pública como divulgação, ou que é para o público, já foi frisada por autores nacionais e internacionais coevos. E ela pode acontecer de várias formas, que podem, ou não, estar envolvidas sob o rótulo de "divulgação de história", que, já se acentuou, é mais que "divulgação científica".

Serge Noiret garante que a tarefa do historiador público é "comunicar publicamente a história". Enquanto Hilda Kean menciona o site Doing Public History como expressão de que a História Pública é, para alguns, "baseada na forma e natureza de transmissão do conhecimento histórico para audiências maiores". ${ }^{34} \mathrm{O}$ site inglês é consultado para promover "convincente reflexão sobre o relacionamento historiador acadêmico e o público". Também John Tosh define História Pública como envolvendo "o livre acesso do público para as descobertas da erudição histórica". ${ }^{35}$ Ele corretamente criticou a definição de História Pública como "uma opção a ser perseguida por um punhado de acadêmicos procurando publicidade". ${ }^{36}$ No entanto, para ele a ênfase em História Pública é tanto sobre "a inserção de perspectiva histórica dentro de questões públicas cruciais" e de acadêmicos "compartilhando com o público sua própria expertise" 37 .

${ }^{33}$ Why would people without either direct personal or professional motivation pay close attention to the complexities of history? Here I mean history in a strong sense - a formal discipline, demanding specialised skills, expertise and knowledge, including a critical understanding of source material and a familiarity with a wide range of ways in which evidence can be interpreted. Ver: JORDANOVA, Ludmila. Como a história importa hoje? Disponível em: http://www.historyandpolicy.org/policypapers/papers/how-history-matters-now. Publicado em novembro de 2008. Acesso em janeiro 2019.

${ }^{34}$ based on the form and nature of transmission of historical knowledge to wider audiences .... is seeking to promote cogent reflection on the relationship between the academic historian and the public. Ver: KEAN, Hilda. Pensando sobre pessoas e história pública. Disponível em http://arts.brighton.ac.uk/_data/assets/pdf_file/0005/68270/Chapter-1-Working-Papers-Journal-byHilda-Kean-ISSN-20458304-.pdf. S.d. Acesso em janeiro 2019.

35 the free access of the public to the findings of historical scholarship. Ver: KEAN, Hilda. Pensando sobre pessoas e história pública. http://arts.brighton.ac.uk/_data/assets/pdf_file/0005/68270/Chapter-1-Working-Papers-Journal-byHilda-Kean-ISSN-20458304-.pdf. S.d. Acesso em janeiro 2019.

36 an option to be pursued by a handful of publicity-seeking academics. Ver: KEAN, Hilda. Pensando sobre pessoas e história pública. Disponível em http://arts.brighton.ac.uk/ data/assets/pdf_file/0005/68270/Chapter-1-Working-Papers-Journal-byHilda-Kean-ISSN-20458304-.pdf. S.d. Acesso em janeiro 2019.

37 is both upon 'the injection of historical perspective into crucial public issues' and of academics 'sharing with the public their own scholarly expertise. Ver: KEAN, Hilda. Pensando sobre pessoas e história pública. Disponível em http://arts.brighton.ac.uk/ data/assets/pdf file/0005/68270/Chapter-1Working-Papers-Journal-by-Hilda-Kean-ISSN-20458304-.pdf. S.d. Acesso em janeiro 2019. 
A análise da História Pública como divulgação entendida como história para o público merece considerações de ordem conceitual com o fim de nuançar o que ela significa e alguns perigos - ou, pelo menos, meias-verdades - em que se pode incorrer.

Alheio a esta primeira colocação, e pertinente à indefinição - ou às definições múltiplas - do que seja História Pública, de fato há uma constante sobre a difusão/divulgação do conhecimento histórico. Que, se a história pública é para o público, ela supõe uma emissão permanente e, mais ainda, quase sempre esta emissão teria um caminho único: de um sujeito sabedor, em quem há um saber/conhecimento, até outro sujeito insipiente, a quem falta o saber/conhecimento que lhe será transmitido. Conn é taxativo.

\begin{abstract}
É nosso trabalho contar a verdade histórica, e é tão importante que nós nomeemos as mentiras históricas. No fim [desta palestra], eu peço a todos vocês considerarem-se historiadores públicos, pedindo que reafirmem nossa expertise. Não é simplesmente porque nós sabemos mais sobre o passado embora nós saibamos - mas nós sabemos como pensar sobre o passado de modos que muitos outros não sabem. Isto é o que temos de oferecer ao debate público e eu insisto com todos encontrarem novos modos de fazer isso. ${ }^{38}$
\end{abstract}

A História Pública é entendida como esclarecimento, produção de conteúdos desmistificantes, isentos de falsidade, e capazes de, de uma vez por todas, informar o que não é equivocado, o que não é falso, e que precisa ser levado a todos para que saiam do disfarce e da ilusão. Conn, na mesma obra, ainda diz: "Fazer história pública significa atuar em favor da difusão de conhecimento histórico para amplas audiências".

Comentando "a quarta capa do livro" Introdução à História Pública, Santhiago discorre sobre divulgação científica e divulgação histórica para ponderar as chances de um entendimento de que - com o que concordo - a divulgação seja considerada como conhecimento feito de maneira mais simples: "Tenho lá minhas dúvidas de que a 'história pública' seja uma forma mais simples de história - mesmo se for, essa

\footnotetext{
${ }^{38}$ It is our job to tell the historical truth, and it is just as important that we call out historical lies. In the end, as I ask you all to consider yourselves public historians, I am asking us all to re-assert our expertise. It is not simply that we know more about the past-although we do-but we know how to think about the past in ways that most others do not. That is what we have to offer to the public debate and I urge you all to find new ways to do it. Ver: KEAN, Hilda. Pensando sobre pessoas e história pública. Disponível em http://arts.brighton.ac.uk/ data/assets/pdf_file/0005/68270/Chapter-1Working-Papers-Journal-by-Hilda-Kean-ISSN-20458304-.pdf. S.d. Acesso em janeiro 2019.
} 
'simplificação' ou 'estetização' é extremamente difícil: uma batalha constante entre conteúdo e apresentação, sem cortes, compressões, diminuições, condensações"39.

Mas o ato comunicativo não pode deixar de ser problematizado.

$\mathrm{O}$ ato comunicativo, e também o postulado de que alguém sabe um saber melhor do que outro, deve ser problematizado. Ato comunicativo, linguagem. Postulado: como saber se alguém sabe mesmo mais do que outro ou sabe diferente do outro? O que garante isso: um ethos, um hábito que ensinou-nos a acreditar numa hierarquia de saberes? Em se tratando da "colaboração" própria à história pública conduzida em museus, Duclos-Orselo apropria-se de afirmação do filósofo Jacques Rancière, e propõe uma via da colaboração entre curadores de museus e visitantes, numa situação em que "alguns que sabem alguma coisa se envolvem com alguns que sabem uma outra coisa". ${ }^{40}$

Questões diversas podem ser levantadas aqui quanto à natureza da divulgação histórica, mormente a dois aspectos: o de que haja alguém que sabe história mais que outros, e a transmite, e o aspecto de que a divulgação histórica só depende de linguagem acessível. Quando na realidade se trata de histórias diferentes. Já ficou comum dizer-se que a História Pública não limita o conhecimento histórico à universidade, à academia, o que precisa ser ponderado. A divulgação pode sugerir um ou ganhar contornos de um conhecimento histórico do historiador que - mesmo sendo um conhecimento especialista que cuida, por convicção conceitual, não se fazer superior previamente conhecimento que estaria acima de um conhecimento histórico comum de públicos não formados, que têm sua própria história e a sabem narrar, mas que, pelas perspectivas de alguns pontos de vista, seria sempre um conhecimento comum e carente de alguma coisa - em síntese, porque não-orientado cientificamente. São públicos que, por isso mesmo, precisariam receber a história especializada do historiador para saber a história que deve ser sabida. Hilda Kean aponta para uma definição muito fechada da relação historiador acadêmico e público, a qual (...) supõe um foco sobre aqueles que são vistos como criadores de história e aqueles que são seus receptores. (...). ao mesmo tempo que engajando o público e relaçando “ (...) o status separado do historiador como o

\footnotetext{
39 SANTHIAGO, Ricardo. Duas palavras, muitos significados: alguns comentários sobre a história pública no Brasil. In: MAUAD, ALMEIDA, Juniele Rabelo de; SANTHIAGO, Ricardo (Orgs.). História Pública no Brasil: Sentidos e Itinerários. SP: Editora Letra e Voz, 2016. p.23-36.

40 where those who know something engage with those who know something else. Ver: DUCLOSORSELO, Elizabeth. Autoridade compartilhada: a chave para educação museal como mudança social. Journal of Museum Education, v.38, n.2, July 2013, p.121-128.
} 
disseminador que não apenas possui o conhecimento, mas a habilidade de transmissão" $" 41$.

A colocação pode induzir a uma impressão bastante disseminada entre o consumidor comum não-formado em história e historiadores experts: a de que a boa história é a que deve ser transmitida pelo expert e, principalmente, como já dissemos, "numa linguagem simples e acessível”. Não se incorre aqui em dois grandes equívocos: um, o de que o receptor é limitado, por isso é preciso simplificar para ele poder aprender (e esse ato de aprender também não é mensurado!)?; e, depois, o equívoco de que o que dificulta as mensagens serem compreendidas seja uma mera questão de linguagem, sem levar em conta a complexidade do que constitui a natureza eventual do que se transmite? Simplificar a linguagem, para bem dizer, não poderia incorrer em extrair do que se transmite a complexidade do que o caracteriza? (não obstante haja não poucos textos acadêmicos que sejam marcados, sim, pela linguagem hermética, como opção narrativa de quem escreve, lastreado que está na formalização da linguagem científica, que conduz ao hermetismo da linguagem compartilhada entre, unicamente, aqueles que participam de uma comunidade de ciência).

(...) A 'divulgação científica' pode sugerir a transmissão de um certo conjunto de conhecimentos de forma 'mais simples', de modo a atingir um público mais amplo - para informá-lo, entretê-lo, diverti-lo. Isso consiste numa simplificação dos padrões já existentes. Não se trata de 'traduzir' de forma simplória o que se produziu cientificamente, mas de dar a conhecer os procedimentos e discuti-los coletivamente, inclusive questionando-os ${ }^{42}$.

Compartilhar é seguramente positivo. É preciso verificar como isso se faz, no entanto. A partir do campo da História Oral, o historiador oral público Michael Frisch firmou o conceito de "autoridade compartilhada", que questiona o que seria uma unidirecionalidade (grifo meu) do discurso do historiador produtor em direção a um público consumidor. O que, para Frisch, "é uma ideia limitada e limitadora de história pública". Egressa da entrevista de história oral, a ideia de "autoridade compartilhada" questiona uma transmissão de saber produtor historiador ao consumidor público sem saber, alterando esta unidireção do diálogo pela ideia de um "diálogo real (grifo do

\footnotetext{
${ }^{41}$ (...) provides a focus upon those who are seen to be creating history and those who are its recipients. In such a definition 'agents' and 'consumers' (...) This has the dual effect of engaging 'the public' but also of enhancing the separate status of the historian as the disseminator who not only possesses knowledge but the skill of transmission. Ver: KEAN, Hilda. Pessoas, historiadores e História Pública. The Public Historian, v.32, n.3, p.25-38, 2010.

42 SANTHIAGO, Ricardo. Duas palavras, muitos significados: alguns comentários sobre a história pública no Brasil. In: MAUAD, ALMEIDA, Juniele Rabelo de; SANTHIAGO, Ricardo (Orgs.). História Pública no Brasil: Sentidos e Itinerários. SP: Editora Letra e Voz, 2016. p.23-36.
} 
autor) no qual fontes e bases de autoridade diferentes têm reivindicações distintas e particulares, que podem competir, ser comparadas, avaliadas e relacionadas por meio daqueles encontros importantes que o cenário da história pública pode apoiar e estimular" $^{\prime 3}$. O espectro do conceito de autoridade compartilhada entre pessoas em diálogo verdadeiro prevê atitudes díspares em que cada autoridade (historiador e público, entrevistado e entrevistador) dispensa à relação passado e presente, reconhecendo e valorizando diferentes modos de configurar esta relação, ora com uma história feita cientificamente, ora com, simplesmente, a humanidade que pessoas partilham. Como adverte Kean acima neste texto. A autora encontra respaldo em experiências que não só criticam certa presunção de superioridade do expert, como também testemunha o espanto do expert ao perceber que, em situações as quais considera "de História Pública", se vê inexpert, uma vez que

\begin{abstract}
pode haver, é claro, uma lacuna em entendimento histórico entre aqueles treinados como historiadores e as audiências para seu trabalho, mas esta lacuna não deve ser diminuída pelos historiadores meramente alcançando "o público". Ao contrário, como David Glassberg sugeriu, novos modos de pensar sobre o passado podem ser compreendidos "alcançando a descoberta da humanidade que eles partilham". O reconhecimento pessoal das necessidades dos historiadores, tanto quanto as do público pelo passado, é chave para diferentes entendimentos do passado. Se história não engloba o reconhecimento do papel das pessoas em fazer história - e inclui historiadores dentro desta ideia das pessoas - isto apresenta desafios. Isso pode ser um pouco inquietante, mas talvez um bom lugar para começar por tornar acessível História Pública e de partilhar ideia ou validar experiência. ${ }^{44}$
\end{abstract}

Também o historiador finlandês Jorma Kalela esteve frente a frente a um público de operários como consultor acadêmico de história para ajudar trabalhadores de fábrica escreverem suas histórias. A certo tempo, o historiador percebe que suas colocações estão prescrevendo o que deve ser aprendido pelos operários, cujos interesses por sua, e abordagem de sua história não tinham, na raiz, as perguntas que o treinamento de

\footnotetext{
${ }^{43}$ FRISCH, Michael. A história pública não é uma via de mão única o de a Shared Authority à cozinha digital, e vice-versa. In: MAUAD, Ana M; ALMEIDA, Juniele R de.; SANTHIAGO, Ricardo. (Orgs.) História Pública no Brasil. Sentidos e Itinerários. São Paulo, SP: Letra e Voz, 2016. p.57-69.

${ }^{44}$ There may, of course, be a gap in historical understandings between those trained as historians and the audiences for their work but this gap will not be shortened by 'historians' merely reaching out to 'the public'. Rather, as David Glassberg has suggested, new ways of thinking about the past may be grasped by 'reaching in to discover the humanity they share'. The recognition of the historian's - as much as the public's - personal need for the past is key to different understandings of the past. 9 If History does embrace an acknowledgement of people's role in making history - and includes historians within this idea of people - this presents challenges.10 It can be an unsettling but perhaps a good place to start in opening up historiographical practice.11 Exploring our engagement with our own and others' pasts may help us develop different ways of thinking about Public History and of sharing ideas or validating - or scrutinising - experience.Ver: KEAN, Hilda. Pensando sobre pessoas e história pública. Disponível em http://arts.brighton.ac.uk/ data/assets/pdf file/0005/68270/Chapter-1-Working-Papers-Journal-byHilda-Kean-ISSN-20458304-.pdf. S.d. Acesso em janeiro 2019.
} 
Kalela o ensinou, em especial como deveria agir para abordar o passado nestas situações. O historiador conta-nos do momento em que ocorreu uma virada na relação dos operários para com seu passado.

Uma vez que aceitaram a ideia de que eles tinham o mesmo direito de definir o conteúdo de história como um historiador profissional, os círculos proliferaram. Este alvoroço era a maneira dura na qual eu descobri que o conceito acadêmico tradicional de história que eu trazia como garantido era, por sua natureza, paternalista. Eles tinham o direito de estudar o que em sua visão era sua própria história, mais do que tomar como certo um conceito pronto disto. ${ }^{45}$

O consultor Jorma Kalela havia criado quarenta círculos de pesquisa entre seu público de trabalhadores e deixou a eles a definição dos parâmetros para fazerem sua história.

Em recente texto, Publicizar sem simplificar. O historiador como mediador ético, Marta Rovai segue a mesma direção. "Pensar a publicização de fatos que envolvem coletividades é pensar nos usos que diferentes setores sociais fazem do passado". Ao relatar sua experiência com comunidades populares, que sabem sua história de um modo que não é o modo de conhecer com que o historiador conhece o passado, a autora assinala que aquelas comunidades "[buscam] defender, preservar e registrar suas histórias e memórias a partir de suas próprias demandas”. Diz a autora:

O trabalho com essas comunidades coloca o historiador diante de novos narradores e de um público que não simplesmente consome, mas participa da construção e das escolhas sobre o que, como e por que e quando divulgar suas histórias. Como profissional e cidadão, de forma mais explícita e necessariamente dialógica, coloca-se diante de novas perguntas sobre os efeitos da produção histórica, da divulgação de novos saberes, da autoria compartilhada e dos benefícios às comunidades com as quais escolhe lidar. ${ }^{46}$

Porque parece certo que a maneira com que historiadores analisam o passado e seu objeto seja condicionada pelas perguntas de método, metodologia, abordagem teórica, relevância do tema, função da história, análise de fontes que marcaram sua formação de historiador com conhecimento cientificamente orientado. Se admitimos

45 Once they had accepted the idea that they had the same right to define the substance of history as a professional historian, the circles proliferated. This agitation was the hard way in which I discovered that the traditional academic concept of history that I had taken for granted was, by its nature, patronizing... They had to have the right to study what in their view was their own history, rather than take for granted a ready-made concept of it. Ver: KALELA, Jorma. Fazer História: o historiador como consultor. Public History Review. v.20, 2013, p.24-41.

${ }^{46}$ ROVAI, Marta G. de O. Publicizar sem simplificar: o historiador como mediador ético. In: ALMEIDA, Juniele R de; MENESES, Sônia (Orgs.). História Pública em debate: patrimônio, educação e mediações do passado. São Paulo, SP; Editora Letra e Voz, 2018. p.185-196. 
que a história pública é a apresentação da história para públicos mais amplos do que os pares acadêmicos, temos de supor que qualquer apresentação de história para públicos seja divulgação - filmes, minisséries, história digital, rádio etc, que apresentam a história? Numa acepção diversa da que pondero aqui, o que Rovai e Kalela fazem aqui não é exatamente divulgação de alguém que sabe para outro que não sabe, mas um processo de relatar resultados que foram deliberadamente construídos a partir de duas expertises: a do profissional historiador e a dos que sabem sua história! - gostemos ou não. Se sabem ou se não sabem, de um ponto de vista do historiador formado, não importa para este debate. O que importa é garantir a legitimidade destas comunidades em saber que eles podem contar suas histórias sem o crivo do historiador profissional com sua colaboração, talvez - e que nem por isso suas histórias serão menos consistentes.

Seria de se perguntar: como escrever história sem se desdenhar dos critérios do público que olha para o passado? A opção será a de advogar mais a defesa de uma História pelo público, mas com a participação do historiador, entendendo como o passado é transformado em história, e considerar como o historiador pode se compor, ou colaborar com outros públicos para que façam suas histórias. ${ }^{47}$

Há experiências com história pública que entendem a história comum do público como tão valorosa quanto a do historiador formado especialista, inclusive admitindo que sua história deve ser estudada e compreendido seu processo de construção - sob que balizas, valores, ideias, ideologias, influências etc. foram elaboradas. O historiador elabora o passado de modo disciplinarizado, o que envolve uma especialização que dirige ao passado perguntas e abordagens que derivam de uma sistemática de abordagem científica que requer um olhar treinado metodologicamente para o passado. O que não é o olhar que outros públicos não-disciplinarizados têm. Deve-se tentar evitar reproduzir, implicitamente, a ideia de que haja, no fim de tudo, uma elaboração do historiador mais adequada do que a de outros públicos, ratificado pelo que disse Albieri, já citada: como se o acesso do historiador "a documentos fosse tudo o que falta para que a revelação iluminadora da verdade histórica finalmente ocorra". A divulgação que mobiliza o material do historiador não pode incorrer neste risco profissional de se

\footnotetext{
47 O historiador holandês Paul Knievel, nos anos 1990, quando da apro’ximação das histórias públicas europeias e americana, registra que a história pública seria, então, redefinida como 'história para o público, sobre o público e feita pelo público, se aproximando da tipificação que depois Santhiago vai firmar na literatura nacional brasileira. A qualificação de história feita pelo público abre margem para uma história do público, história da própria lavra do público, feita por ele.
} 
imaginar aquele que, tendo o acesso aos documentos, têm o condão de fazer com que a verdade histórica apareça?

A divulgação de História deve se assemelhar mais a um trabalho colaborativo, onde o historiador colabora com outros públicos a fim de tomarem o passado com balizas de interpretação de suas realidades individuais e sociais capazes de favorecer a outros públicos a olhar seu passado, dando sentido a ações no presente e a projeções de futuro. E mesmo fornecendo balizas as quais, mesmo se próprias de um especialista treinado, podem favorecer o olhar dos que se voltam para o passado e não têm formação científica para tal.

\section{Considerações Finais - procedimentos para um encaminhamento por meio da recuperação da legitimidade da fala}

A nosso ver, por hipótese, talvez a divulgação da história que se quer levada para "amplas audiências" - como sendo este seu motivo principal - precisaria, acima de tudo, uma audiência disponível para a História, ou para a palavra do historiador. Sem desprezar o fato de que audiências não necessariamente estejam lá, esperando histórias, mas que elas criam suas histórias próprias e se satisfazem com elas. Sem se precisar exatamente quem sejam estas audiências, sem se localizar onde elas estão e podem ser encontradas, pergunta-se se a histórica pública profissional brasileira estaria disposta a considerar ir além, se estaria disposta a discutir não só sobre seu lugar de fala, mas o que tem deteriorado a autoridade que, supostamente, garantiu a historiadores durante muito tempo esta autoridade legitimada e reconhecida. Hoje, vivemos um estado da arte em que a autoridade do historiador está questionada e deslegitimada por "fazedores de história" que, muito embora façam usos do passado sem os critérios que garantem interna corporis - a autoridade historiadora, têm-na esvaziado dos historiadores, ocupando seus lugares. É contra qualquer intenção dos historiadores profissionais de menosprezarem, e de evitarem enfrentar, a corrosão de sua autoridade por nãohistoriadores midiáticos que escrevem histórias muitas vezes metodologicamente questionáveis, que motiva Jurandir Malerba firmar que é "imperiosa a necessidade de os historiadores acadêmicos entrarem nesse debate, inclusive por cuidado para com o ensino e as práticas didáticas"48.

\footnotetext{
${ }^{48}$ MALERBA, Jurandir. Acadêmicos na berlinda ou como cada um escreve a História?: uma reflexão sobre o embate entre historiadores acadêmicos e não acadêmicos no Brasil à luz dos debates sobre Public History. Revista História da Historiografia, Ouro Preto, n.15, p. 27-50, agosto de 2014.
} 
A meu ver, a divulgação de história no Brasil - e talvez não só no Brasil requer, primeiro, recuperar este lugar de fala e sua autoridade, a fim de legitimar o historiador profissional, acadêmico, como seja, a dizer sobre o passado e ser acreditado, porém sempre pensado como portador de uma das visões possíveis do passado, uma vez firmando os historiadores o monopólio de dizer o passado. A realidade perceptiva dos consumidores de história, grosso modo, parece-nos, irrefletidamente, condenar o que se fala sem antes mesmo de ouvir, sendo suas afirmações triadas por e permeadas de fatores contextuais e ambientais marcados por profundas disputas de narrativas de memória e polarizações político-ideológicas vincadas muitas vezes pelo uso do passado por meio de má-fé, interesses particularistas, ou desconhecimento mesmo, desdobrado, possivelmente, da percepção autêntica - feliz ou infelizmente - de que ninguém é dono do passado e de suas interpretações.

Os exemplos da França e do Reino Unido comparados por Stevens são instrutivos. A autoridade francesa dos historiadores reunidos numa corporação acadêmica que sustenta corrente historiográfica de tradição internacional sobre o que se diz do passado conduziu mesmo a institucionalização de um comitê associativo de vigilância dos usos públicos do passado na França. ${ }^{49}$ Por mais que historymakers alheios ao universo acadêmico produzam história e usem o passado a seu modo, a autoridade dos historiadores franceses se faz valer em meio a uma cultura de história em que os historiadores profissionais são voz ativa e requisitados para dizer o passado, ou mesmo profissionais que intervêm sobre afirmações públicas, corrigindo-as, sem que sejam deslegitimados - muitas vezes dando a entender que a interpretação sobre a história tem lugar principal e alguns têm o monopólio do uso do passado. Como se fossem juízes do passado.

O caso inglês, contrário ao francês, parece deslocar-se da mesma fonte de legitimidade francesa - com aspectos tanto perigosos como estratégicos para a autolegitimidade dos que fazem história. No Reino Unido, para a comunidade de historiadores, a realidade que predomina é a de que todos têm e sabem sua história - e aí reside um perigo. Porque, para historiadores não-formados ingleses e seus públicos, a

\footnotetext{
${ }^{49} \mathrm{O}$ CVUH francês (Comité de Vigilance face aux usages publiques de l'histoire - Comitê de Vigilância Face aos Usos públicos da história e do passado) é uma associação de historiadores francesa criada para fiscalizar os usos particulares, políticos, oportunistas de temas públicos, visando controlar sua divulgação e aqueles usos quando lançam mão de acontecimentos e processos passados para se legitimarem. Foi criado em 2005, por ocasião das discussões em torno da lei de 23 de fevereiro de 2005. Nela, era decretado que os manuais escolares deveriam exaltar o papel colonizador da França em suas ex-colônias, celebrando a França. Contra a lei levantaram-se vários historiadores, em torno de cuja movimentação foi criado o CVUH.
} 
história é parte integrante de suas vidas, mas sempre a história entendida como valor individual, importante porque a inscrição da história de coletivos é realizada em suas vidas individuais, e nelas se bastam. Arriscamo-nos a dizer, uma história despolitizada. Mas tenhamos cuidado, porque é história despolitizada em termos.

Despolitizada em termos, uma vez que as políticas que são consideradas são as políticas públicas e tudo aquilo que diz respeito ao ser individual, tomado como lócus de emoção e passado nostálgico, ou resultado de condicionantes passados chegados pelo tempo até o presente. A história na cultura pública histórica que os ingleses reconhecem - similar ao que pecebem os americanos brancos em geral - é a de suas próprias vidas individuais entendidas como "históricas" - sem interligações com grandes questões e dramas coletivamente vividos e partilhados. Se perigoso - e em dissenso como uma história que nos ensina nossa localização social como parte de um todo coletivo relacional - é benfazejo que os ingleses não pensem assim, uma vez que, não tendo ninguém o monopólio da história, fazem do passado o que querem: entretenimento, diversão, lugares de passeio e lembranças, relíquias e antiguidades, curiosidades. Muito parecido com a realidade americana. A história não tem uma função política pública, mas apenas uma função social, e assim mesmo à medida que ajuda a soldar solidariedades mínimas, entendidas estas como solidariedades de família, de lugares e pequenas cidades, e mais ainda como solidariedade nacional. Stevens registra, da parte do historiador francês, uma indignação com a perda de uma "autoridade de reconhecimento", fato que parece não abalar o historiador inglês, e mesmo o americano. Enquanto na França e na Alemanha, a reação contra a "mitologização romântica" da história - por exemplo com Michelet - tomou forma na criação de uma disciplina histórica nacional, enquadrando a função da história a ser divulgada pelo professor como depositária do nacionalismo, a mesma sorte não se passou na Inglaterra, “onde a ideia nacional desenvolveu-se independentemente e grandemente antes do nacionalismo romântico"50 com o que a história não se desenvolveu como um "secular sacerdócio".

(...) Na França, como no mundo germânico, a reação contra a mitologização romântica tomou a forma da emergência da historiografia como uma disciplina intelectualmente distinta. Isto pode ser contrastado com a situação na Inglaterra, onde a ideia nacional desenvolveu-se independentemente e

\footnotetext{
${ }^{50}$ where the national ideal developed both independently and largely in advance of Romantic nationalism. Ver: STEVENS, Mary. Política pública e o historiador público: os diferentes lugares de historiador na vida pública na França e no Reino Unido. The Public Historian, v.32, n.3, 2010 p.120-135.
} 
grandemente antes do nacionalismo romântico. (...) em geral historiadores não têm, na Inglaterra, constituído, da mesma forma, um secular sacerdócio. ${ }^{51}$

Nos Estados Unidos, as associações de historiadores de família e de histórias locais são poderosas, além de criadoras de postos de trabalho. David Thelen e Roy Rosenweig desenvolveram pesquisa de opinião importante neste sentido, e, por mais polêmica que tenha sido, no entanto foi pesquisa que lhes deu base empírica, por meio de respostas dos públicos mesmos, para rebaterem afirmações que censuravam os americanos de não terem preocupação com sua história, e se se preocupavam com ela e usavam-na. ${ }^{52}$ Este fundamento da História Pública americana, se provê em legitimidade pública o trabalho de scholars historiadores - há sempre lugar para serem ouvidos, e eles são ouvidos legitimamente - por outro lado provê, a nosso ver, um perigoso faz de conta. Se a história dos americanos reconhecida por eles só se conecta por meio de suas narrativas pessoais de vida, por outro lado os americanos parecem naturalizar o fato de que, como plano de fundo da aceitação desta história individualizada, está a validação de um passado nacional comum - na história muito bem construído e constantemente reiterado em mídias diversas, em especial o cinema - passado percebido como sem conflitos, sem discórdias e guerras - e com dose grande de diversidade reprimida - o que garante circunscrever seus passados individuais descolados de seus passados coletivos.

A tentativa de reescrita do passado colonial francês em 2005 por Sarkozy, do que gerou a criação da CVUH, pretendendo exaltar a colonização francesa na África, por outro lado, foi prontamente rebatida por historiadores, que vieram a público retrucar o presidente pelo que consideravam um uso do passado equivocado, ideologizado e inaceitável, e devidamente interpretado para ser reescrito. No Reino Unido, e nos Estados Unidos, controvérsias pontuais sobre usos do passado tornam-se pontuais, e não alteram aquele plano de fundo que faz da história que as amplas audiências contam e respeitam consubstanciadas num passado comum mitificado.

${ }^{51}$ In France, as in the Germanic world, the backlash against Romantic mythologization took the form of the emergence of historiography as a distinct scholarly discipline. This can be contrasted with the situation in Britain, where the national ideal developed both independently and largely in advance of Romantic nationalism (...) in general, historians have not in Britain constituted a secular priesthood in quite the same way. Ver: STEVENS, Mary. Política pública e o historiador público: os diferentes lugares de historiador na vida pública na França e no Reino Unido. The Public Historian, v.32, n.3, 2010 p.120-135.

52 David Thelen e Roy Rosenweig publicaram pela primeira vez, em 1998, The presence of the past: popular uses of History in American Life (A presença do passado: usos populares da história na vida americana). Pesquisa feita por telefone com uma amostra nacional de 808 entrevistados e três amostras separadas, de mais ou menos 200 cada, de afro-americanos, mexico-americanos e índio-americanos. 
A meu ver, é por meio de uma investigação profunda sobre o que fez o esvaziamento da autoridade acadêmica do historiador, e sua deslegitimação para dizer o passado, ${ }^{53}$ que deve começar um plano de divulgação da História. É preciso, não sabemos como, reconquistar - se é que um dia tivemos - um lugar de fala, revesti-lo ao ponto de as "amplas audiências", antes mesmo de nos ouvirem, aceitarem que temos de ser ouvidos. Que sabemos também o passado, a nossa maneira, mas que sabemos um conhecimento que não é melhor nem pior que outros, mas diferente, produzido por critérios que não são aqueles critérios e parâmetros com que muitos que escrevem a história não profissionalmente o fazem. Antes do desafio, há um desafio antes: como contar com a confiança das audiências? "O historiador não detém e nunca deterá o monopólio desta fala [da história] (e isso é saudável)" ${ }^{\text {". }}$.

Entre disputas por narrativas históricas, há um outro aspecto a ponderar: como sermos ouvidos, escutados, sem que nos ouçam com preconceitos que levam a fala do historiador para o plano daquilo de que não se precisa, ou não deve ser escutado, porque é um "doutrinador" que fala, item da agenda investigativa nos diversos trabalhos que apontam o projeto da Escola Sem Partido como projeto que qualifica o professor de História como "doutrinador". Este é um desafio muito grande antes, a meu ver, de discutirmos os termos com que falamos e de que lado estamos quando falamos. É preciso, primeiro, firmar o respeito de sermos legitimamente ouvidos: “(...) a questão da legitimidade dos trabalhos acadêmicos continua a ser importante (...) o que se coloca em questão é certa postura arrogante que tratava a produção vinda da academia como a única capaz de ter um certificado, um lastro" "55. A questão da legitimidade parece estar sendo enfrentada se tivermos em mente o conjunto já grande de textos elaborados sob a rubrica genérica da "função do historiador intelectual público" que participa de debates e da esfera pública com seus posicionamentos.

Fazendo assim, presumo, estaremos mais prontos para divulgar nosso conhecimento, e ouvir as críticas que tiverem de ser perpetradas, uma vez que nosso conhecimento será legitimado como um dos conhecimentos possíveis de serem

\footnotetext{
${ }^{53}$ Aqui, neste ponto, Jurandir Malerba reclama do espaço perdido por historiadores profissionais para historiadores leigos e sem formação metódica, a partir de uma bibliografia basicamente americana sobre o assunto. Em suma, "qualquer um pode escrever história, o que não significa que toda história tenha o mesmo valor e qualidade", segundo o autor.

${ }^{54}$ TEIXEIRA, Ana Paula T; CARVALHO, Bruno Leal P de. Introdução: os lugares do historiadordivulgador. In: História Pública e divulgação da História. São Paulo (SP): Letra e Voz, 2019. p.9-24.

${ }^{55}$ MAUAD, Ana M; ALMEIDA, Juniele R de.; SANTHIAGO, Ricardo. (Orgs.) História Pública no Brasil. Sentidos e Itinerários. São Paulo, SP: Letra e Voz, 2016. Resenha de: CORRÊA, Luiz Otávio. Os vários significados da História Pública. Revista Transversos, Rio de Janeiro, v.7, n.7, set.2016.
} 
enunciados, ouvidos no debate público. Principalmente para nos ajudar a compreender que nosso pensamento não é superior e que não estamos fazendo a difusão do que é certo para pessoas inscientes e sem conhecimento algum de história, uma vez que, gostemos ou não, todos têm - e criam - histórias. Importa é reconhecer que, bem ou mal, audiências têm conhecimento, que não pode ser condenado ou negado, apenas retrucado e rebatido. Com formas firmadas na igualdade de fala e, claro, com iguais condições de emissão. Da mesma maneira que Marieta de Moraes Ferreira está preocupada com que qualquer cidadão não tem legitimidade para fazer história científica como os cientistas da história fazem, também os cientistas da história devem se preocupar com o reconhecimento dos limites de seu saber a fim de participar do debate público. Porque senão corremos o risco de ficarmos sem compreender por que, tão conscientes da história científica, somos, da parte do público, tão substituídos pelos não-treinados em história quando se trata de falar e dizer a história.

Data de submissão: $22 / 04 / 2020$

Data de aceite: $24 / 06 / 2020$ 


\section{Referências bibliográficas}

ALBIERI, Sara. História pública e consciência histórica. ALMEIDA, Juniele Rabêlo de \& ROVAI, Marta Gouveia de Oliveira. Introdução à História Pública. São Paulo: Letra e Voz, 2011.

ARIÉS, Philippe et al. A história - uma paixão nova. In: LE GOFF; LADURIE; DUBY.et al.A Nova História. Lisboa, PO: Edições 70, s.d. p.9-40

BANN, Stephen. As invenções da história: ensaios sobre a representação do passado. Ed. UNESP, 1994.

CAUVIN, Thomas. Uma ascensão da história pública: uma perspectiva internacional. Revista NUPEM, v.11, n.23, p. 8-28, 2019.

CONN, Steven. Mensagem presidencial: cada historiador um historiador público. Disponível em: https://www.ohioacademyofhistory.org/wpcontent/uploads/2019/01/Proceedings-2018-Presidential-Address-Steve-Conn_EveryHistorian-a-Public-Historian.pdf. S.d. Acesso em setembro 2018.

COSTA, Marcela Albaine Farias da; MENDES, Caroline Alves Marques. O sequestro do imaginário e a escrita da história: o caso dos memes históricos e a recepção do Nazismo. Revista

DUCLOS-ORSELO, Elizabeth. Autoridade compartilhada: a chave para educação museal como mudança social. Journal of Museum Education, v.38, n.2, July 2013, p.121-128.

FERREIRA, Marieta de Moraes. Uma trajetória em (o que chamamos hoje) História Pública. Revista História Hoje, v.8, n.15, p.223-238, 2019. Entrevista concedida a Miriam Hermeto e Rodrigo de Almeida Ferreira.

FRISCH, Michael. A história pública não é uma via de mão única o de a Shared Authority à cozinha digital, e vice-versa. In: MAUAD, Ana M; ALMEIDA, Juniele R de.; SANTHIAGO, Ricardo. (Orgs.) História Pública no Brasil. Sentidos e Itinerários. São Paulo, SP: Letra e Voz, 2016. p.57-69.

HAMEROW, Theodore. The Bureaucratization of History. The American Historical Review, v.94, n.3, p.654-660. Jun.1989.

HERMETO, Miriam \& FERREIRA, Rodrigo de A. Apresentação de dossiê. Revista História Hoje, v.8, n.15, p.5-16, 2019.

JORDANOVA, Ludmila. Como a história importa hoje? Disponível em: .http://www.historyandpolicy.org/policy-papers/papers/how-history-matters-now.

Publicado em novembro de 2008. Acesso em janeiro 2019.

KALELA, Jorma. Fazer História: o historiador como consultor. Public History Review. v.20, 2013, p.24-41.

KEAN, Hilda. Pessoas, historiadores e História Pública. The Public Historian, v.32, n.3, p.25-38, 2010. 
KEAN, Hilda. Pensando sobre pessoas e história pública. Disponível em http://arts.brighton.ac.uk/_data/assets/pdf_file/0005/68270/Chapter-1-Working-PapersJournal-by-Hilda-Kean-ISSN-20458304-.pdf. S.d. Acesso em janeiro 2019

LE GOFF, Jacques. Reflexões sobre a História. Lisboa, PO: Edições 70, s.d.

MALERBA, Jurandir. Acadêmicos na berlinda ou como cada um escreve a História?: uma reflexão sobre o embate entre historiadores acadêmicos e não acadêmicos no Brasil à luz dos debates sobre Public History. Revista História da Historiografia, Ouro Preto, n.15, p. 27-50, agosto de 2014.

MAUAD, Ana M; ALMEIDA, Juniele R de.; SANTHIAGO, Ricardo. (Orgs.) História Pública no Brasil. Sentidos e Itinerários. São Paulo, SP: Letra e Voz, 2016. Resenha de: CORRÊA, Luiz Otávio. Os vários significados da História Pública. Revista Transversos, Rio de Janeiro, v.7, n.7, set.2016.

NOIRET, Serge. Internacionalizar a história pública. Outubro $\underline{2014}$ Disponível em: https://public-history-weekly.degruyter.com/2-201434/internationalizing-public-history/. Acesso em março 2019.

PENNA, Fernando de Araujo \& FERREIRA, Rodrigo de Almeida. O trabalho intelectual do professor de História e a construção da educação democrática. Prática de História Pública frente à Base Nacional Comum Curricular e ao Escola Sem Partido. In: História Pública em debate: patrimônio, educação e mediações do passado. São Paulo, SP; Editora Letra e Voz, 2018. p.109-127.

ROSENZWEIG, Roy.; DAVID, Helen T. A presença do passado: Usos populares da história na vida americana. New York: Columbia University Press, 1998.

ROVAI, Marta G. de O. Publicizar sem simplificar: o historiador como mediador ético. In: ALMEIDA, Juniele R de; MENESES, Sônia (Orgs.). História Pública em debate: patrimônio, educação e mediações do passado. São Paulo, SP; Editora Letra e Voz, 2018. p.185-196.

ROVAI, Marta G. de O. Ensino de História e a História Pública. Os testemunhos da Comissão Nacional da Verdade em Sala de Aula. Revista História Hoje, v.8, n.15, p.89-110, 2019.

SANTHIAGO, Ricardo. "A História Pública é a institucionalização de um espírito que muitos historiadores têm tido, por milhares de anos": Uma entrevista com David King Dunaway sobre História Oral, História Pública e o passado nas mídias. Revista Transversos. "Dossiê: História Pública: Escritas Contemporâneas de História". Rio de Janeiro, Vol. 07, $\mathrm{n}^{\circ}$. 07, pp. 203-222, Ano 03. set. 2016. Disponível em: <http://www.e-publicacoes.uerj.br/index.php/transversos>. ISSN 2179-7528. DOI: 10.12957/transversos.2016.25607.

SANTHIAGO, Ricardo. Duas palavras, muitos significados: alguns comentários sobre a história pública no Brasil. In: MAUAD, ALMEIDA, Juniele Rabelo de; SANTHIAGO, Ricardo (Orgs.). História Pública no Brasil: Sentidos e Itinerários. SP: Editora Letra e Voz, 2016. p.23-36. 
SANTHIAGO, Ricardo. A história pública no Brasil entre práticas e reflexões. Revista Observatório. v.3, n.2, abril/junho 2017. Entrevista concedida a Fagno da Silva Soares

SARLO, Beatriz. Tempo Passado. Cultura da Memória e Guinada Subjetiva. São Paulo (SP): Cia das Letras; Belo Horizonte (MG): Editora UFMG, 2007.

STEVENS, Mary. Política pública e o historiador público: os diferentes lugares de historiador na vida pública na França e no Reino Unido. The Public Historian, v.32, n.3, 2010 p.120-135.

TEIXEIRA, Ana Paula T; CARVALHO, Bruno Leal P de. Introdução: os lugares do historiador-divulgador. In: História Pública e divulgação da História. São Paulo (SP): Letra e Voz, 2019. p.9-24.

TOSH, John. Why History Matters. Londres (Inglaterra): Palgrave Macmillan, 2008.

VERGO, Peter. The New Museology. Islington: Reaktion Books, 1989. 